\title{
Effects of administration of testosterone, dihydrotestosterone, oestrogen and fadrozole, an aromatase inhibitor, on sex skin colour in intact male rhesus macaques
}

\author{
L. Rhodes ${ }^{1}$, M. E. Argersinger ${ }^{2}$, L. T. Gantert ${ }^{1}$, B. H. Friscino ${ }^{1}$, \\ G. Hom ${ }^{I}$, B. Pikounis ${ }^{\text {I }}$, D. L. Hess ${ }^{3}$ and W. L. Rhodes ${ }^{4}$ \\ ${ }^{1}$ Merck Research Laboratories, Merck and Co. Inc., PO Box 2000, Rahway, NJ 07065, USA; ${ }^{2}$ College of \\ Veterinary Medicine, Cornell University, Ithaca, NY 14853, USA; ${ }^{3}$ Oregon Regional Primate Research \\ Center, 505 NW 185th Avenue, Beaverton, OR 97006, USA; and ${ }^{4}$ Chromatech, Inc., Boulder,
} CO 80302, USA

\begin{abstract}
For defining the mechanism of control of sex skin colour in male rhesus macaques (Macaca mulatta) by hormones, a spectrocolorimeter was used to monitor skin redness after administration of testosterone, dihydrotestosterone (a non-aromatizable androgen), oestradiol or fadrozole (an aromatase inhibitor that blocks the conversion of testosterone to oestrogen). Skin blood flow was measured by laser doppler. Eight 9-14 kg, 5-9 year old intact male rhesus macaques were given hormone, fadrozole or vehicle treatments in a cross-over experimental design. Baseline blood flow and colour measurements were taken in four paired tattoo defined areas on the back and legs of each animal (one pair in non-sex skin, three pairs in sex skin). Colour and blood flow measurements were taken 3-4 days after the first dose and, thereafter, once a week for 3-6 weeks. Measurements taken after treatments were compared with baseline and intra-animal comparisons were made between treatment and vehicle for each animal. In all animals after administration of $4 \mathrm{mg}$ testosterone $\mathrm{kg}^{-1}$ (long-acting), redness in the sex skin areas increased $(P=0.032)$ by day 3 and returned to baseline values by day 7 . Administration of $1 \mathrm{mg}^{\text {oestradiol }} \mathrm{kg}^{-1}$ day $^{-1}$ for 4 days caused increased redness in all animals $(P=0.007)$ similar in magnitude to that caused by testosterone. Administration of $0.1 \mathrm{mg}$ dihydrotestosterone $\mathrm{kg}^{-1} \mathrm{day}^{-1}$ for 4 days resulted in a nonsignificant decrease in redness $(P=0.09)$ on days $3-7$. Treatment with fadrozole $\left(0.25-0.5 \mathrm{mg} \mathrm{kg}^{-1}\right.$ day $\left.^{-1}\right)$ for 3 weeks caused sex skin to become significantly less red during treatment $(P=0.014)$. There was no significant change in redness in non-sex skin areas during any treatment. Sex skin blood flow increased in animals treated with testosterone, correlating with increased redness $(R=0.906)$, while blood flow in non-sex skin was unchanged. Increased redness after treatment with testosterone and oestrogen, no change in redness with treatment with dihydrotestosterone and a decrease in redness after treatment with fadrozole support the conclusion that oestrogen controls sex skin redness, and testosterone acts indirectly through conversion to oestrogen to cause increased sex skin redness in male rhesus macaques.
\end{abstract}

\section{Introduction}

Adult males and females of a number of species of non-human primates have regions of 'sexual' or 'sex' skin. These are areas of epidermis in the face, outer canthal area, circumanal area, perineum, and the area surrounding the ischial callosities. In male rhesus macaques (Macaca mulatta), as well as in other species (for example, baboons), these areas display a seasonal increase in red colour and tissue swelling. In other primates, such as talapoin monkeys (Miopithecus talapoin), the sex skin is blue. The existence of sex skin has been known for more than

Received 4 April 1997. a century, but its function and the factors regulating the colour change are not well defined. It is presumed to have a role in sexual signalling and dominance.

The correlation of the appearance of sex skin reddening and the mating season has been observed in both sexes in free-range and laboratory settings (Baulu, 1976; Bielert and Vandenbergh, 1981). The seasonal changes in sex skin have been correlated with changes in testicular histology (Vandenbergh, 1965). A similar correlation between seasonal breeding activity and increased concentrations of circulating testosterone has been demonstrated in male rhesus monkeys (Gordon et al., 1976). Testosterone concentrations have been linked directly with changes in sex skin colour; castratisis. 
causes a decrease in the redness that can be restored by administration of testosterone or oestradiol (Vandenbergh, 1965; Michael and Wilson, 1974). In contrast, administration of testosterone did not cause an increase in the redness of sex skin in intact free-ranging male rhesus macaques (Baulu, 1976).

Oestrogen and ovarian activity have been linked to alterations in sex skin characteristics in female non-human primates for many years (Michael and Saayman, 1968; Czaja et al., 1977; Carlisle ef al., 1978). Sex skin areas became pale in female rhesus macaques after ovariectomy and increased swelling of sex skin was observed in those with a cystic ovarian follicle (Zuckerman et al., 1938; Herbert, 1970). Similarly, in pigtail macaques (Macaca nemestrina), sex skin redness peaks have been shown to be an index of the onset of ovulation (Bullock et al., 1972). Systemic concentrations of oestradiol have also been shown to increase just before the breeding season in male rhesus macaques (Bercovitch, 1992) suggesting that both testosterone and oestrogen are involved in sex skin reddening. However, it is not known whether testosterone increases redness by aromatization to oestrogens, or if both androgens and oestrogens have direct effects on redness.

For defining the mechanism of the control of sex skin coloration by hormones, sex skin redness and serum concentrations of testosterone, dihydrotestosterone and oestrogen were monitored after administration of testosterone, dihydrotestosterone and oestradiol. Fadrozole, an aromatase inhibitor that blocks the conversion of testosterone to oestrogen (Santen et al., 1991), was used to test the hypothesis that testosterone causes reddening via metabolism to oestrogens (Bonsall et al., 1992; Zumpe et al., 1993). The precision of detection of sex skin colour was increased by using a reflectance spectrocolorimeter rather than the visual assessment of redness used in previous studies. Therefore, the data generated are less subjective and allow specific analysis of changes in the different aspects of colour change, including redness and intensity. In a further experiment, skin blood flow was measured to test the hypothesis that increased redness is accompanied by an increase in skin blood flow.

\section{Materials and Methods}

\section{Animals}

Eight $9-14 \mathrm{~kg}, 5-9$ year old, adult intact male rhesus macaques (Macaca mulatta) from Merck Research Laboratories, Rahway, NJ were prospectively evaluated. All animals were housed, in accordance with American Association for Accreditation of Laboratory Animal Care (AAALAC) standards, in an individual cage in sight of all other animals in the room. Animals were maintained on standard food, water and environmental enrichment programmes. The lighting in the room was maintained at $12 \mathrm{~h}$ light: $12 \mathrm{~h}$ dark. Experimental protocols were approved by the Institutional Animal Care and Use Committee (IACUC) of Merck Research Laboratories.

\section{Study design}

Each animal was given hormone treatments and vehicle in a cross-over design since sex skin colour patterns vary widely among animals. All studies were performed on eight animals, administering either testosterone, oestradiol, fadrozole (an aromatase inhibitor), or corresponding vehicles. Dihydrotestosterone was given to five animals in a cross-over design with vehicle controls. Animals were assigned randomly to treatment or vehicle periods of the study. On day 1 of each study, the animals were anaesthetized, and baseline blood samples and colour measurements were taken as described below. During one experiment (Expt A: treatment with testosterone and dihydrotestosterone), blood flow was measured after the colour measurements. Animals were then given the treatments in the dosages described below. Colour measurements, skin blood flow measurements (during one experiment only) and blood samples were repeated 3-4 days later and, thereafter, once a week for 3-6 weeks, depending on treatment. Between treatment periods of the study, 3-4 weeks of rest were allowed.

\section{Anaesthesia and blood sampling}

Animals were anaesthetized with ketamine $\mathrm{HCl}$ and xylazine administered intramuscularly each day that colour and skin blood flow measurements were taken. Animals received 70-110 mg ketamine $\mathrm{HCl}$ (Ketaset ${ }^{\mathrm{B}}$, Fort Dodge and Co., Fort Dodge, IA) and 4-10 mg xylazine (Rompun ${ }^{(1)}$, Miles, Shawmee Mission, KS). This allowed about $20 \mathrm{~min}$ for blood sampling, colour measurements, and treatments. Blood samples $(10 \mathrm{ml})$ were drawn from the femoral vein. Since serum androgens have been shown to have a diurnal rhythm in rhesus macaques (Chambers and Phoenix, 1981), samples were drawn between approximately 09:00 $\mathrm{h}$ and 12:00 $\mathrm{h}$ each day to minimize the diurnal variability of the serum hormones. Blood was allowed to clot and centrifuged at $2060 \mathrm{~g}$ for $20 \mathrm{~min}$. Serum was stored at $-80^{\circ} \mathrm{C}$ until analysis.

\section{Hormone assays}

Serum samples were assayed for testosterone, dihydrotestosterone and oestradiol by radioimmunoassay. After extraction with ether, hormones were separated by column chromatography and assayed as described by Resko et al. (1980). Average recoveries were $75 \%, 75 \%$ and $79 \%$ for testosterone, dihydrotestosterone and oestradiol, respectively. All samples to be assayed for each hormone were run in one assay to minimize variability. Intra-assay coefficients of variation were $3.4 \%$, $8.7 \%$ and $14.3 \%$ for testosterone, dihydrotestosterone and oestradiol, respectively.

\section{Colour measurements}

Measurements were taken of skin colour in four marked pairs of areas on the back and legs of each rhesus (Fig. 1). Each pair of areas was bilaterally symmetrical and equidistant from the spine. Areas to be measured were marked at the beginning of the experiments using a cloth template fitted over the tail and centered on the spine to standardize marked areas between animals. Holes in the cloth defined the spots for measurement. Each site was permanently tattooed with two dots, placed so that they did not affect colour measurements, defining a circle 


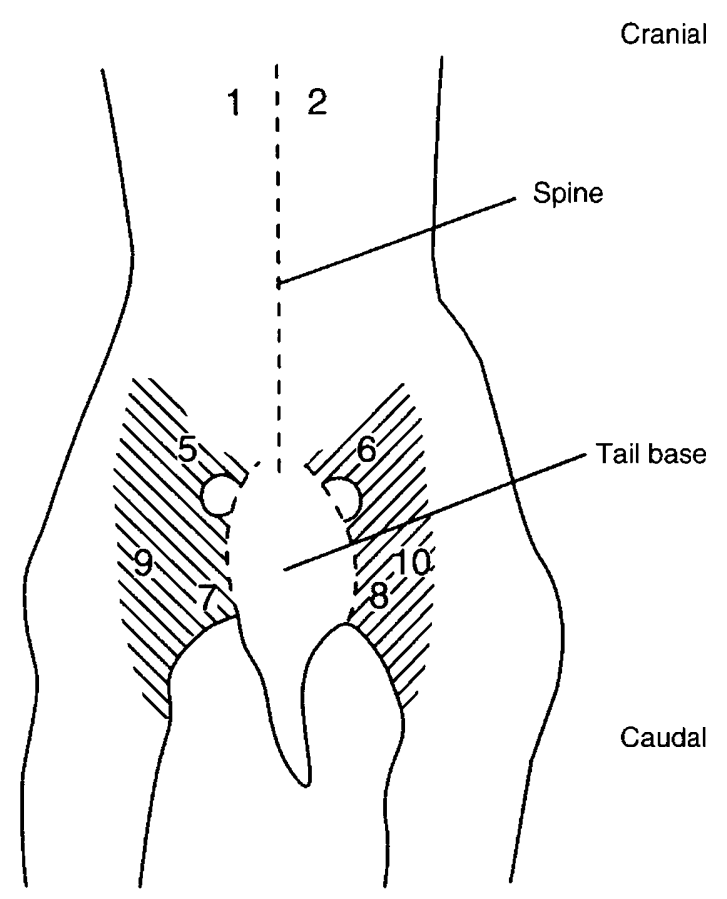

Fig. 1. Approximate areas of non-sex skin ( 1 and 2 ) and sex skin (5-10) where colour and blood flow measurements were taken in each male rhesus macaque.

about $2.5 \mathrm{~cm}$ in diameter. Areas 1 and 2 were located in non-sex skin in the upper back. (Areas 3 and 4 were also in non-sex skin, but since their measurements were consistent with areas 1 and 2, they were not measured in all experiments and are not included in the analysis.) All other areas were located in the sex skin around the tail (areas 5 and 6), and on the medial (areas 7 and 8) and caudal (areas 9 and 10) aspects of the thighs.

\section{Spectrocolorimetry}

A spectrocolorimeter $\left(948\right.$ X-Rite ${ }^{(i i i) ~ C o r p ., ~ s e r i a l ~ n u m b e r ~}$ L-41737) with a $20 \mathrm{~mm}$ aperture was used to measure skin colour. The illuminance was set at F2 for cool white fluorescence. The colorimeter took three readings sequentially and automatically averaged them to yield mean values for six variables. Three values in a standard colour reference system were recorded for each animal: $L, a$, and $b$. Briefly, each value represents a calculated point in a three-dimensional colour space. The $L, a$ and $b$ values represent points on the light-dark, red-green and yellow-blue axes, respectively. The spectrocolorimeter was calibrated to a white reference standard at the start of each data collection day.

\section{Skin blood flow}

After colour measurements were taken, skin blood flow was monitored in the same location in animals treated with testosterone by laser doppler (Perimed; Piscataway, NJ) using a PF 315 integrating probe. The probe was placed sequentially on each of the eight spots designated for colour measurement, and each reading was taken over $15-30 \mathrm{~s}$. Skin blood flow was recorded in laser doppler units (LDF).

\section{Treatments}

After the collection of blood samples and baseline colour measurement, the animals were administered a hormone, drug or vehicle according to the cross-over design described above. Dosages for the hormone treatments were based on the mean bodyweight of animals, and were kept at a constant volume. For fadrozole treatment, the dosage was adjusted to the bodyweight of each individual animal. Bodyweights were measured weekly.

For testosterone treatment, animals were dosed with testosterone enanthate (Delatestryl ${ }^{3 i}$, Squibb) i.m. at a dose of $40 \mathrm{mg}$ $\left(0.2 \mathrm{ml}\right.$, approximately $\left.4 \mathrm{mg} \mathrm{kg}^{-1}\right)$. This dosage is long-acting and was, therefore, given only once per treatment period. Matching vehicle was one i.m. injection of $5 \%$ ethanol:95\% cottonseed oil. Animals receiving dihydrotestosterone were dosed with $1 \mathrm{mg}^{-1}$ day $^{-1}\left(0.2 \mathrm{ml}\right.$; approximately $\left.0.1 \mathrm{mg} \mathrm{kg}^{-1}\right)$ i.m. for 4 days. Matching vehicle was 5\% ethanol:95\% cottonseed oil given i.m. for 4 days. Animals receiving oestradiol were dosed with $10 \mu \mathrm{g}$ oestradiol day ${ }^{-1}(0.2 \mathrm{ml}$, approximately $1 \mu \mathrm{g} \mathrm{kg}^{-1}$ ) for 4 days, and matching vehicle was $5 \%$ ethanol:95\% cottonseed oil given i.m. for 4 days. After the initial week of exposure to hormones, animals were monitored for 3-4 weeks to allow washout of the steroids between treatment periods of the study. On days when animals were not anaesthetized for colour measurements, they received the injections while in their cages. Control animals were given vehicle (5\% ethanol:95\% cottonseed oil) i.m. on a schedule matching the hormone treatments.

Fadrozole (Fd: CGS16949A: 4-(5,6,7,8-tetrahydroimidazo[1,5 $\alpha$-pyridin-5-yl) benzonitrile monohydrochloride, synthesized by Merck Research Laboratories, Rahway, NJ, or its vehicle (sterile water) was administered using an osmotic minipump (Alza Corp., Palo Alto, CA) as described by Zumpe et al. (1993). Each animal received $0.25 \mathrm{mg}$ fadrozole $\mathrm{kg}^{-\mathrm{T}}$ day $^{-1}$ (15.9 $\mathrm{mg} \mathrm{ml}^{-1}$ solution) or an equivalent volume of vehicle (sterile water). Osmotic pumps were implanted in anaesthetized animals s.c. between the scapulae, using sterile technique. After the 2 week treatment, the pumps were removed from anaesthetized animals using sterile technique and animals were continued on injections of a higher dose of $0.5 \mathrm{mg}$ fadrozole $\mathrm{kg}^{-1} \mathrm{day}^{-1}\left(9 \mathrm{mg} \mathrm{ml}^{-1}\right.$ solution) or vehicle given twice a day, i.m. for 7 days.

\section{Drug formulation}

Dihydrotestosterone solutions were made up as follows: $5 \alpha$-androstan 17 $\beta$-ol-3-one (DHT: lot\#19F0183: Sigma Chemical Co., St Louis, MO) was dissolved in ethanol and filter sterilized into a sterile nitrogen purged vial using a disposable sterile syringe filter $(25 \mathrm{~mm}, 0.2 \mu \mathrm{m}$, nylon membrane polypropylene; Corning Inc., NY). After sterile filtration of the dihydrotestosterone-ethanol solution, cottonseed oil was added through the $0.2 \mu \mathrm{m}$ filter. The final concentration was $5 \mathrm{mg}$ dihydrotestosterone $\mathrm{ml}^{-1}$ in $5 \%$ ethanol:95\% cottonseed oil. 
Table 1. Mean \pm SEM change scores of sex skin redness ${ }^{a}$ from intact male rhesus macaques treated with either vehicle, testosterone, dihydrotestosterone, oestrogen or fadrazole in each experimental group (cross-over design)

\begin{tabular}{|c|c|c|c|c|}
\hline Experiment & Treatment & $n$ & $\begin{array}{c}\text { Change score } \\
\text { mean } \pm \text { SEM }\end{array}$ & $\begin{array}{c}P \text { value versus } \\
\text { vehicle }\end{array}$ \\
\hline \multirow[t]{3}{*}{ A } & Vehicle & 6 & $0.83 \pm 0.49$ & \\
\hline & Testosterone & 8 & $2.34 \pm 0.29$ & 0.032 \\
\hline & Dihydrotestosterone & 5 & $-0.29 \pm 0.56$ & 0.09 \\
\hline \multirow[t]{2}{*}{ B } & Vehicle & 8 & $0.31 \pm 0.31$ & \\
\hline & Oestrogen & 8 & $2.11 \pm 0.31$ & 0.007 \\
\hline \multirow[t]{2}{*}{$\mathrm{C}$} & Vehicle & 8 & $0.17 \pm 0.63$ & \\
\hline & Fadrazole & 8 & $-2.92 \pm 0.63$ & 0.014 \\
\hline
\end{tabular}

"Variable a

Oestradiol solutions were made by dissolving 1,3,5[10]oestradiol-3,17 $\beta$-diol (lot\#121H0117, Sigma) in ethanol, and filter sterilizing as described above for dihydrotestosterone. After filtration of the oestradiol-ethanol solution, cottonseed oil was added through the sterile filter. Final concentration was $50 \mu \mathrm{g}$ oestradiol $\mathrm{ml}^{-1}$ in $5 \%$ ethanol:95\% cottonseed oil.

Fadrozole was dissolved in water at a concentration of $15.9 \mathrm{mg} \mathrm{ml}^{-1}$ or $9 \mathrm{mg} \mathrm{ml}^{-1}$ for administration by Alzet pump or injection, respectively. The solution was filter sterilized as described above.

\section{Statistical analysis}

For a given animal and experimental phase of the cross-over, there were repeated measures, including 5-6 post-treatment colour readings and serum hormone measurements, and each reading was performed in eight skin areas. A summary colour measure was defined thus: the average colour reading (variable a) of the non-sex skin sites ( $n=2$ per animal) and the average of the sex skin sites ( $n=6$ per animal) by time and experiment were calculated for each subject. The average for the non-sex skin was subtracted from the average for the sex skin and the average of these differences over time minus the differences at baseline were calculated for each animal and each experiment. This value was called a change score response. It integrated the total change in sex skin colour over the 3 weeks after each treatment for each animal compared with the baseline value. Serum testosterone, dihydrotestosterone and oestradiol values were also measured at timepoints across subject and experiment, and change score responses were calculated in a similar manner for these variables. However, for the hormone measurements, timepoints only up to 1 week after treatment were used, since hormones were administered for 1 week or less. Since fadrozole was administered for 3 weeks, the data for this 3 week period were used.

The summary change scores were compared using a $2 \times 2$ cross-over analysis and differences were considered significant at $P<0.05$. All assumptions required for the validity of the statistical analyses on the change scores were found to be reasonably satisfied by graphical and formal methods.

\section{Results}

\section{Skin colour}

The results of the spectrocolorimeter colour measurements showed consistently that the redness $(a)$ values were inversely proportional to the lightness $(L)$ values. This result confirms the intuitive observation that redder colours were darker. It was also observed that the values on the yellow-blue axis $(b)$ also covaried with the red-green $(a)$ values. Therefore, it was decided to base the analysis on the a variable alone, since that was the most direct and true measure of sex skin redness.

Significant variability in sex skin redness between animals and over time in individual animals was observed. Non-sex skin remained a relatively constant pale colour, and did not vary with any of the treatments (data not shown).

Treatment with testosterone and oestradiol caused a significant increase in redness in the sex skin areas $(P=0.032$ and $P=0.007$, respectively), while treatment with vehicle had no consistent effect on redness (Table 1 ). The increase in redness was seen at the first measurement after hormone treatment ( 3 days after initiation of treatment) and gradually declined over the 3 weeks after treatment was discontinued.

Administration of dihydrotestosterone caused a slight decrease in sex skin redness that was not statistically significant $(P=0.09)$ but was consistent in all monkeys treated with dihydrotestosterone $(n=5)$.

Treatment with fadrozole for 3 weeks caused a marked decrease in sex skin redness $(P=0.014)$. During the first week of treatment, changes were relatively modest; by weeks 2-3 the full effect was observed (Fig. 2).

\section{Blood flow}

Blood flow in the non-sex skin measured near zero, while flows in the sex skin ranged from a low of 10 units to high values of 100-120 units. Like sex skin colour, blood flow was highly variable among and within animals. In spite of this variability, there was a clear correlation between increases in sex skin redness induced by testosterone treatment and increases in blood flow $(R=0.906)$. The smoothing curve indicates the pattern of correlation to be very close to that of 


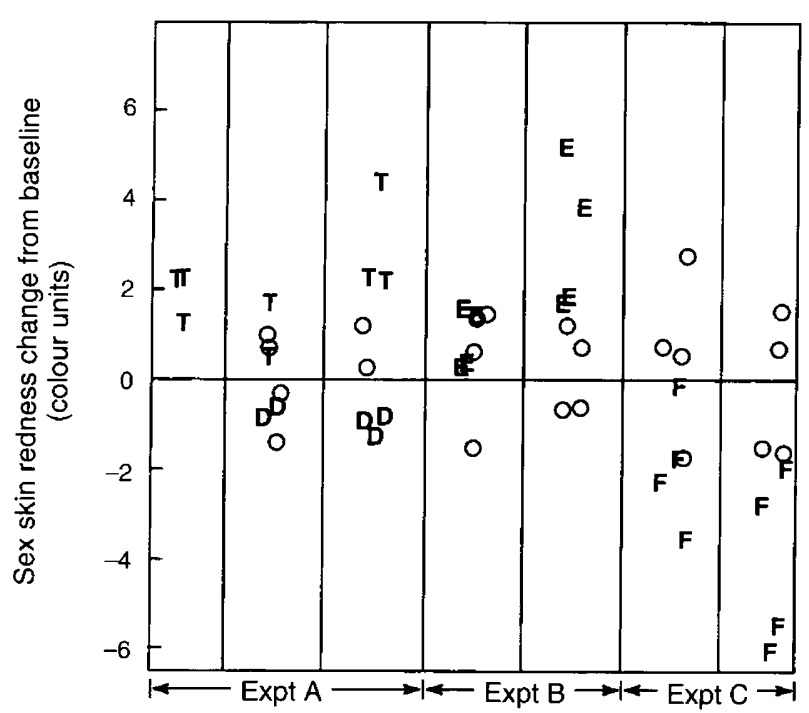

Fig. 2. Individual animal change scores for sex skin redness (average difference from baseline over 3 weeks) from all treatment groups in each period of the crossover studies. $T$, testosterone; $D$, dihydrotestosterone; $\mathrm{E}$, oestradiol; F, fadrozole; $\mathrm{O}$, vehicle treatments. Expt $\mathrm{A}$ included treatments with testosterone $(n=8)$, dihydrotestosterone $(n=5)$ and vehicle $(n=6)$; Expt B included treatments with oestradiol $(n=8)$ and vehicle $(n=8)$; and Expt $C$ included experiments with fadrozole $(n=8)$ and vehicle $(n=8)$.

a straight line. In animals treated with DHT, there was no increase in redness or blood flow (Fig. 3). Blood flow in non-sex skin areas did not change with either testosterone or dihydrotestosterone treatment. (Blood flow was not measured during other hormone treatments.)

\section{Serum hormones}

Treatment with testosterone increased blood concentrations of testosterone, dihydrotestosterone and oestradiol (Table 2). Treatment with dihydrotestosterone also increased serum dihydrotestosterone concentrations but had no significant effects on testosterone or oestradiol. Treatment with oestradiol did not consistently increase serum oestradiol, nor did it have measurable effects on testosterone or dihydrotestosterone. Fadrozole caused a significant decrease in serum oestradiol concentrations $(P=0.004 ;$ Table 2$)$.

\section{Discussion}

The results of this study support previous findings that testosterone is an important hormone in the control of sex skin redness in male rhesus macaques (Vandenbergh, 1965; Michael and Wilson, 1974; Baulu, 1976). In previous studies, it was not clear whether this was due to direct binding of the androgen receptor, or to the effects of testosterone metabolites. In selected tissues, the enzymes $5 \alpha$-reductase and aromatase convert testosterone to dihydrotestosterone or oestradiol, respectively. Dihydrotestosterone cannot be aromatized to oestrogen and, therefore, major effects of dihydrotestosterone are due to direct binding of the androgen receptor. Since

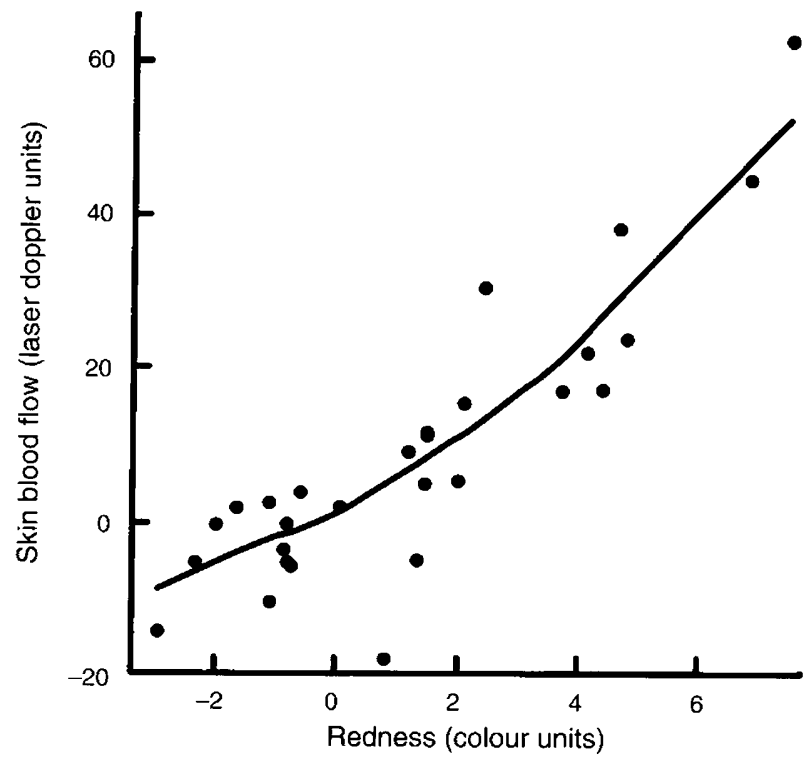

Fig. 3. Blood flow and skin redness measured in eight anaesthetized rhesus macaques multiple times over the course of 2 weeks. Animals were treated with testosterone, dihydrotestosterone or vehicle. Three days after treatment, they were anaesthetized again and skin blood flow and skin redness measured. This plot represents the change from baseline in skin blood flow (laser doppler units) and skin redness (colorimetry units) in the various skin areas measured in each animal. The correlation between blood flow and redness is 0.906 . A smoothing curve (Cleveland, 1979) for all data points is overlaid.

both testosterone and dihydrotestosterone bind the androgen receptor (although with different affinities), effects that occur with administration of testosterone, but not of dihydrotestosterone, can be hypothesized to require the aromatization of testosterone to oestrogens.

In this study, sex skin redness increased when intact animals were administered oestrogen even though increases in serum oestradiol were not detected. This supports the hypothesis that the increase in redness is caused by an increase in tissue oestrogen concentrations. Increases in sex skin swelling and redness in response to oestrogen have been noted in female rhesus macaques for many years (Zuckerman et al., 1938; Herbert, 1970; Czaja et al., 1977; Wallen and Goy, 1977). Similar findings have also been observed in pigtail macaques (Carlisle et al., 1981). In these studies, serum oestrogen correlates with increases in redness, in contrast to our findings in males where no correlation was found. However, serum oestrogen in cyclic females peaks between 100 and $300 \mathrm{pg}$ $\mathrm{ml}^{-1}, 10-100$ times higher than the concentrations measured in male rhesus macaques. It may be that biologically significant changes in oestrogen concentrations in males are too small for our assay to measure. Another possibility is that, because post-treatment samples were collected $24 \mathrm{~h}$ after the last injection, serum oestrogens may have cleared more rapidly than tissue oestrogens.

The lack of change in sex skin redness in animals administered dihydrotestosterone also supports the hypothesis that redness is caused by oestrogen since dihydrotestosterone, unlike testosterone, cannot be aromatized to oestrogens. An aromatase inhibitor such as fadrozole inhibits the conversion of 
Table 2. Mean \pm SEM change scores of serum hormone concentrations from intact male rhesus macaques treated with either vehicle, testosterone, dihydrotestosterone or fadrazole in each experimental group (cross-over design)

\begin{tabular}{|c|c|c|c|c|c|}
\hline \multirow[b]{2}{*}{ Experiment } & \multirow[b]{2}{*}{ Treatment } & \multirow[b]{2}{*}{$n$} & \multicolumn{3}{|c|}{ Change score (mean \pm SEM) } \\
\hline & & & Dihydrotestosterone & Testosterone & Oestrogen \\
\hline \multirow[t]{3}{*}{ A } & Vehicle & 6 & $-0.81 \pm 0.31$ & $1.65 \pm 2.28$ & $-0.63 \pm 5.41$ \\
\hline & Testosterone & 8 & $0.87 \pm 0.19^{*}$ & $21.5 \pm 1.36^{*}$ & $20.79 \pm 3.22^{*}$ \\
\hline & Dihydrotestosterone & 5 & $0.81 \pm 0.35^{*}$ & $-1.69 \pm 2.59$ & $-4.25 \pm 6.13$ \\
\hline \multirow[t]{2}{*}{ B } & Vehicle & 8 & $-0.08 \pm 0.11$ & $0.07 \pm 1.00$ & $-2.00 \pm 0.93$ \\
\hline & Oestrogen & 8 & $-0.16 \pm 0.12$ & $0.31 \pm 1.16$ & $-2.79 \pm 1.07$ \\
\hline \multirow[t]{2}{*}{ C } & Vehicle & 8 & $0.14 \pm 0.06$ & $0.88 \pm 1.79$ & $2.92 \pm 1.01$ \\
\hline & Fadrazole & 8 & $0.33 \pm 0.06$ & $4.26 \pm 1.18$ & $-7.10 \pm 1.01^{*}$ \\
\hline
\end{tabular}

*Significantly different compared with treatment with vehicle $(P<0.01)$.

testosterone to oestrogen (Lipton et al., 1990) and blocks oestrogen-driven behaviours such as ejaculatory activity and sexual motivation in male cynomolgus monkeys (Macaca fascicularis) and male rats (Rattus norvegicus) (Bonsall et al., 1992; Zumpe et al., 1993). In the present study, the fact that fadrozole decreased sex skin redness while dihydrotestosterone had no effect suggests that the aromatization of testosterone to oestrogen, rather than direct androgen action, is a necessary step in the mechanism of the control by hormones of sex skin redness in male rhesus macaques.

The measurements of sex skin colour in the present study were taken with a reflectance spectrocolorimeter, which is an improvement over previous methods using visual comparison of skin colour to Munsell colour chips (Cleveland et al., 1943; Vandenbergh, 1965; Dixson and Herbert, 1974; Michael and Wilson, 1974; Vandenbergh and Drickamer, 1974; Baulu, 1976; Bielert and Vandenbergh, 1981) or by scoring based on visual assessment of estimated colour intensity (Czaja and Bielert, 1975; Czaja et al., 1975; Wallen and Goy, 1977). The spectrocolorimeter was able to quantify small colour differences during the experiment.

The function of sex skin has not been determined definitively. It has been suggested that in pigtail macaques and rhesus monkeys it is a sexual display, conveying hormonal status to members of the opposite sex (Herbert, 1970; Bullock et al., 1972). It has also been shown that the presence of sexually active females can cause an increase in sex skin reddening among free-ranging rhesus males (Vandenbergh and Drickamer, 1974). Sex skin redness has been suggested to be linked with dominance and social rank (Vandenbergh, 1965; Vandenbergh and Drickamer, 1974). However, some data have revealed that dominance rank is not significantly correlated with mean testosterone concentrations during the mating season, although the highest ranking male had the greatest testosterone concentration (Bercovitch, 1993). High testosterone concentrations, dominance rank and increased sex skin redness could, independent of each other, be causes or consequences of increased social interactions with sexually active females.

It is interesting to note that, although testosterone is often considered the most important male reproductive hormone, it appears from the results of the present study that oestrogen, traditionally defined as primarily a female hormone, regulates sex skin colour. Other studies have implicated oestrogen as an important male hormone by demonstrating that increased oestrogen concentrations in reproductive strategies enable male rhesus macaques to forego feeding in favour of reproduction during the breeding season (Bercovitch, 1992). The role of oestrogen in male sexual behaviour has also been studied in male pigtail macaques (Zumpe et al., 1993) in which it was shown that, when the aromatization of testosterone to oestrogen was blocked, ejaculatory activity and sexual motivation were decreased.

The present study shows that the increase in sex skin redness corresponds to an increase in blood flow, but the mechanism for this is unknown. It has been demonstrated that testosterone (Yue et al., 1995) and oestrogen (Gilligan et al., 1994; Williams, et al., 1994) may affect vasomotor function by inducing relaxation of vascular tissue. Whether the vasodilation is a direct or indirect effect on vascular smooth muscle is unclear. Yue et al. (1995) suggest that vasorelaxation induced by testosterone is endothelium independent and does not involve vasodilators such as nitric oxide and prostaglandins but may be the result of alterations in the vascular smooth muscle potassium channel.

Since testosterone can be metabolized to oestrogen, it is possible that the increase in skin blood flow may be induced by oestrogen. Administration of oestrogen to premenopausal cynomolgus monkeys has been shown to result in significant reductions in systemic vascular resistance and increases in cardiac output (Williams et al., 1994). Gilligan et al. (1994) suggest that oestrogen may enhance the actions of endothelium dependent vasodilators. It is known that vascular tone can be regulated by the endothelium via release of nitric oxide (Moncada, 1992; Nathan, 1992). Thus, it is possible that increased concentrations of oestrogen may exacerbate the effects of endogenous vasodilators to produce vasorelaxation. Hence, increases in skin blood flow induced by testosterone may be the result of an effect on vascular smooth muscle that occurs through increased concentrations of oestrogen affecting endothelium-dependent vasodilators.

The question remains as to why this effect is specific to the sex skin regions when systemic hormone concentrations increase with exogenous treatment. The answer may be that 
this skin develops oestrogen receptors after puberty and is, therefore, more sensitive to changes in oestrogen concentrations. There have been no published studies of oestrogen receptors in the sex skin areas of male rhesus macaques but in the female chimpanzee (Ozasa and Gould, 1982) and pigtail macaque (Carlisle et al., 1981) sex skin has been shown to possess significant numbers of oestrogen receptors, while they are absent in non-sex skin. Alternatively, there may be increased concentrations of aromatase in these tissues, leading to increased local production of oestrogen. In a small sample of peripheral tissues, no aromatase activity was found in the sex skin of female rhesus macaques (males were not measured; Martel et al., 1994). The mechanism by which oestrogen acts to increase blood flow and, therefore, redness in the sex skin of rhesus macaques remains to be determined.

The authors thank the staff at the Oregon Regional Primate Research Center for their help in the endocrine assays; J. Mahoney of the Laboratory for Experimental Surgery in Primates of the New York University Medical Center for helpful discussions regarding colour measurement in rhesus; and J. Stone, (Genetics Institute) for surgical assistance. R. Goy, Professor Emeritus of the University of Wisconsin also provided helpful discussions.

\section{References}

Baulu J (1976) Seasonal sex skin colouration and hormonal fluctuations in free-ranging and captive monkeys Hormones and Behavior 7 481-494

Bercovitch FB (1992) Oestradiol concentration, fat deposits, and reproductive strategies in male rhesus macaques Hormones and Behavior 26 272-282

Bercovitch FB (1993) Dominance rank and reproductive maturation in male rhesus macaques (Macaca mulatta) Journal of Reproduction and Fertility $\mathbf{9 9}$ $113-120$

Bielert C and Vandenbergh JG (1981) Seasonal influences on births and male sex skin colouration in rhesus monkeys (Macaca mulatta) in the southern hemisphere Journal of Reproduction and Fertility 62 229-233

Bonsall RW, Clancy AN and Michael RP (1992) Effects of the nonsteroidal aromatase inhibitor, fadrozole, on sexual behavior in male rats Hormones and Behavior 26 240-254

Bullock DW, Paris CA and Goy RW (1972) Sexual behaviour, swelling of the sex skin and plasma progesterone in the pigtail macaque Journal of Reproduction and Fertility 31 225-236

Carlisle KS, Raugi G and Roman NA (1978) Hormonal regulation of the sex skin of nonhuman primates Journal of Cell Biology 79 109A

Carlisle KS, Brenner RM and Montagna W (1981) Hormonal regulation of sex skin in Macaca nemestrina. Biology of Reproduction 25 1053-1063

Chambers KC and Phoenix CH (1981) Diurnal patterns of testosterone, dihydrotestosterone, oestradiol and cortisol in serum of rhesus males: relationship to sexual behavior in aging males Hormones and Behavior 15 416-426

Cleveland WS (1979) Robust locally weighted regression and smoothing scatterplots Joumal of the American Statistical Association 74 829-836

Cleveland R, Wilkes S and Sabotka G (1943) Color measurement of the sexual skin of the macaques rhesus by the Munsell system of color annotation Endocrinology 33 289-296

Czaja JA and Bielert C (1975) Female rhesus sexual behavior and distance to a male partner: relation to stage of the menstrual cycle Archives of Sexual Behavior 4 583-597

Czaja JA Eisele SG and Goy RW (1975) Cyclical changes in the sexual skin of female rhesus: relationships to mating behavior and successful artificial insemination Federation Proceedings 34 1680-1684
Czaja JA, Robinson JA, Eisele SG, Scjeffler G and Goy RW (1977) Relationship between sexual skin colour of female rhesus monkeys and midcycle plasma levels of oestradiol and progesterone Journal of Reproduction and Fertility $\mathbf{4 9}$ $147-150$

Dixson AF and Herbert J (1974) The effects of testosterone on the sexual skin and genitalia of the male talapoin monkey Journal of Reproduction and Fertility $38217-219$

Gilligan DM, Badar DM, Panza JA, Quyyum, AA and Cannon RO (1994) Acute vascular effects of estrogen in postmenopausal women Circulation 90 786-791

Gordon TP, Rose RM, and Bernstein IS (1976) Seasonal rhythm in plasma testosterone levels in the rhesus monkey (Macaca mulatta): a three year study Hormones and Behavior 7 229-243

Herbert J (1970) Hormones and reproductive behaviour in rhesus and talapoin monkeys Journal of Reproduction and Fertility Supplement 11 119-140

Lipton A, Harvey HA, Demers LM, Hanagan JR, Mulagha MT, Kochak GM, Fitzsimmons S, Sanders SI and Santen RJ (1990) A phase I trial of CGS I6949A; a new aromatase inhibitor Cancer 65 1279-1285

Martel C, Melner MH, Gagné D, Simard J and Labrie FD (1994) Widespread tissue distribution of steroid sulfatase, $3 \beta$-hydroxysteroid dehydrogenase/

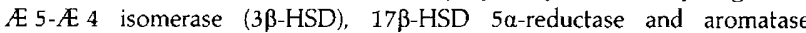
activities in the rhesus monkey Molecular and Cellular Endocrinology 104 103-111

Michael RP and Saayman GS (1968) Differential effects on behaviour of the subcutaneous and intravaginal administration of oestrogen in the rhesus monkey (Macaca mulatta) Journal of Endocrinology 41 231-246

Michael RP and Wilson M (1974) Effects of castration and hormone replacement in fully adult male rhesus monkeys (Macaca mulatta) Endocrinology 95 150-159

Moncada S (1992) The 1991 Ulf van Euler lecture: the L-arginine:nitric oxide pathway Acta Physiologica Scandinavia 145 201-227

Nathan C (1992) Nitric oxide as a secretory product of mammalian cells Federation Association for the Society of Experimental Biology Journal 63051 3064

Ozasa H and Gould K (1982) Demonstration and characterization of the estrogen receptor in chimpanzee sex skin: correlation between nuclear receptor levels and degree of swelling Endocrinology 111 125-131

Resko JA, Ellinwood WE, Pasztor LM and Allen E (1980) Sex steroids in the umbilical circulation of fetal rhesus monkeys from the time of gonadal differentiation Journal of Clinical Endocrinology and Metabolism 50 900-905

Santen RJ, Demers LM, Lynch J, Harvey H, Lipton A, Mulagha M, Hanagan J, Garber JE, Henderson IC, Navari RM and Miller AA (1991) Specificity of low dose fadrozole hydrochloride (CGS 16949A) as an aromatase inhibitor Journal of Clinical Endocrinology and Metabolism 73 99-106

Vandenbergh JG (1965) Hormonal basis of sex skin in male rhesus monkeys General and Comparative Endocrinology 5 31-34

Vandenbergh JG and Drickamer LC (1974) Reproductive coordination among free-ranging rhesus monkeys Physiology and Behavior 13 373-376

Wallen K and Goy RW (1977) Effects of estradiol benzoate, estrone and propionates of testosterone or dihydrotestosterone on sexual and related behaviors of ovariectomized rhesus monkeys Hormones and Behavior 9 228-248

Williams JK, Kim YD, Adams MR, Chen M, Myers AD and Ramwell PW (1994) Effects of estrogen on cardiovascular responses of premenopausal monkeys Journal of Pharmacology and Experimental Therapeutics 271 671-676

Yue P, Chatterjee K, Beale C, Poole-Wilson P and Collins P (1995) Testosterone relaxes rabbit coronary arteries and aorta Circulation 91 1154-1160

Zuckerman S, van Wagenen G and Gardiner RH (1938) The sexual skin of the rhesus monkey Proceedings of the Zoological Society of London 108 $385-401$

Zumpe D, Bonsall RW and Michael RP (1993) Effects of the nonsteroidal aromatase inhibitor, fadrozole, on the sexual behavior of male cynomolgus monkeys (Macaca fascicularis) Hormones and Behavior 27 200-215 